\title{
Anesthetic management of a patient with nitric acid inhalation injury for extracorporeal membrane oxygenation
}

\author{
Yoon-Sook Lee, Se-Hwa Lee, Woon-Young Kim, Jae-Hwan Kim, and Young-Cheol Park \\ Department of Anesthesiology and Pain Medicine, Korea University Ansan Hospital, Ansan, Korea
}

Nitric acid $\left(\mathrm{HNO}_{3}\right)$ is frequently used as a solvent, pickling agent, for etching, and as a cleanser. $\mathrm{HNO}_{3}$ fumes may also contain a mixture of $\mathrm{HNO}_{3}$ with various oxides of nitrogen $\left(\mathrm{NO}, \mathrm{NO}_{2}\right)[1]$. Accidental spillage of $\mathrm{HNO}_{3}$ generates nitrogen oxides that cause chemical pneumonitis when inhaled. In mild cases, there may be no symptoms during the first few hours after exposure, or the typical symptoms of pulmonary edema can appear within 3-24 hours. However, in cases of prolonged exposure, progressive pulmonary edema develops instantaneously, and patients may not survive for more than 24 hours [2]. Treatment of massive pulmonary edema due to increased microvascular permeability is multimodal and comprises mechanical ventilation with positive end expiratory pressure (PEEP), inverse ratio ventilation, replacement of surfactant, and extracorporeal membrane oxygenation (ECMO) [3]. In this report, we describe a case of intravenous anesthesia of nitric acid inhalation injury for ECMO.

A 42-year-old man was accidentally exposed to a toxic mixture for approximately $5 \mathrm{~min}$. He worked for an electroplating factory and was exposed to nitric acid. Initially, he experienced a mild oropharyngeal irritation. But approximately $1 \mathrm{~h}$ later, dyspnea developed, and he was admitted to the emergency department due to dyspnea at rest and cyanosis 2.5 $\mathrm{h}$ after the inhalation. On arrival, he was conscious and well oriented. Expiratory stridor, intercostal muscle retraction, and a frothy secretion from the nose and mouth were noticed. Blood pressure (BP) was 140/74 mmHg with heart rate (HR) of 134/ min and respiratory rate of $28 / \mathrm{min}$. Arterial blood gas analysis (ABGA) showed hypoxemia $\left(\mathrm{pH}, 7.34 ; \mathrm{PaCO}_{2}, 38.5 \mathrm{mmHg}\right.$;
$\mathrm{PaO}_{2}, 60.6 \mathrm{mmHg} ; \mathrm{HCO}_{3}{ }^{-}, 18.9 \mathrm{mmol} / \mathrm{L} ; \mathrm{SaO}_{2}, 87.9 \%$ ). A chest radiograph showed pulmonary edema with confluent alveolarinfiltration densities. Although mechanical ventilation was applied with PEEP at $10 \mathrm{cmH}_{2} \mathrm{O}$ on $100 \%$ inhaled oxygen, the impaired oxygenation worsened. At $4 \mathrm{~h}$ after exposure, despite mechanical ventilation with PEEP at $10 \mathrm{cmH}_{2} \mathrm{O}$ and $\mathrm{FiO}_{2}$ of 1.0, ABGA showed pH, 7.09; $\mathrm{PaCO}_{2}, 108.1 \mathrm{mmHg} ; \mathrm{PaO}_{2}, 43.6$ mmHg; $\mathrm{HCO}_{3}{ }^{-}, 31.8 \mathrm{mmol} / \mathrm{L} ; \mathrm{SaO}_{2}, 58.5 \%$.

As the patient's respiratory situation did not improve, twin pulse extracorporeal life support system (T-PLS ${ }^{\circledR}$, NewHeartbio, Seoul, Korea) was started. ECMO was set to $3.0 \mathrm{~L} / \mathrm{min}$ through the femoral artery and vein. Two $\mathrm{h}$ later, blood gases improved temporarily ( $\mathrm{pH}, 7.324 ; \mathrm{PaCO}_{2}, 49.5$ mmHg; $\mathrm{PaO}_{2}$, $85.8 \mathrm{mmHg}$; $\mathrm{HCO}_{3}{ }^{-}, 25.2 \mathrm{mmol} / \mathrm{L}, \mathrm{SaO}_{2} 95.5 \%$ ), but the pulmonary edema on a chest radiograph worsened. Another $2 \mathrm{~h}$ later, because the femoral venous catheter was inadequate to provide sufficient venous drainage, the venous cannulas were attempted to change from the left femoral vein to the right internal jugular vein. On arrival in the operating room, BP was 100/70 $\mathrm{mmHg}$, $\mathrm{HR}$ was $110 / \mathrm{min}$, and $\mathrm{SpO}_{2}$ was $100 \%$. The intravenous infusion of $2 \mu \mathrm{g} / \mathrm{kg} / \mathrm{min}$ midazolam was discontinued and propofol was infused at $2 \mathrm{mg} / \mathrm{kg} / \mathrm{h}$. A wire-reinforced endotracheal tube was placed after administration of $0.6 \mathrm{mg} / \mathrm{kg}$ rocuronium. Central venous pressure was maintained at $13-15 \mathrm{cmH}_{2} \mathrm{O}$. ABGA at $\mathrm{FiO}_{2}$ of 0.6 showed pH, 7.298; $\mathrm{PO}_{2}, 175.9$ mmHg; $\mathrm{PCO}_{2}, 50.4$ mmHg; $\mathrm{SaO}_{2}, 99.4 \%$; $\mathrm{HCO}_{3}{ }^{-}, 24.1 \mathrm{mmol} / \mathrm{L}$. Approximately 30 min after the propofol infusion, BP decreased to $80 / 60 \mathrm{mmHg}$ and HR increased to $150 / \mathrm{min}$. Phenylephrine $(100 \mu \mathrm{g})$ was injected and infused continuously. But, the patient became

Corresponding author: Yoon-Sook Lee, M.D., Department of Anesthesiology and Pain Medicine, Korea University Ansan Hospital, 516, Gojan 1-dong, Danwon-gu, Ansan 425-707, Korea. Tel: 82-31-412-5316, Fax: 82-31-412-5294, E-mail: yslee4719@yahoo.co.kr (c) This is an open-access article distributed under the terms of the Creative Commons Attribution Non-Commercial License (http:// creativecommons.org/licenses/by-nc/3.0/), which permits unrestricted non-commercial use, distribution, and reproduction in any medium, provided the original work is properly cited. 


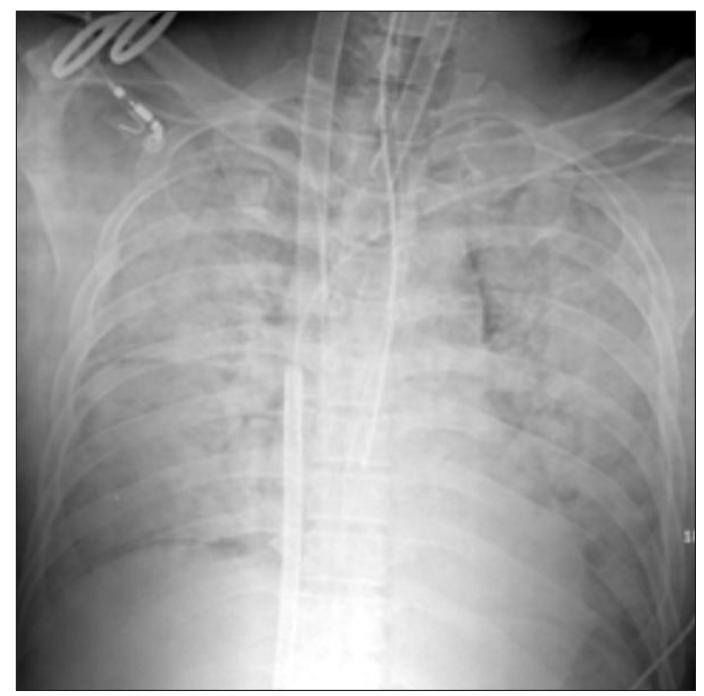

Fig. 1. After extracorporeal membrane oxygenation is applied, a chest radiograph demonstrates diffuse interstitial infiltrates and ground glass opacities in both lungs.

refractory to the infusion of phenylephrine. $\mathrm{ABGA}$ at $\mathrm{FiO}_{2}$ of 0.6 showed pH, 7.271; $\mathrm{PO}_{2}, 108.7$ mmHg; $\mathrm{PCO}_{2}, 47.4 \mathrm{mmHg} ; \mathrm{SaO}_{2}$, 97.1\%; $\mathrm{HCO}_{3}{ }^{-}, 21.3 \mathrm{mmol} / \mathrm{L}$. SBP ranged from $40-60 \mathrm{mmHg}$, so $8 \mathrm{mg}$ ephedrine and $100 \mu \mathrm{g}$ epinephrine were injected. Dopamine (3-15 $\mu \mathrm{g} / \mathrm{kg} / \mathrm{min})$, dobutamine (3-20 $\mu \mathrm{g} / \mathrm{kg} / \mathrm{min})$, and epinephrine $(0.05-1 \mu \mathrm{g} / \mathrm{kg} / \mathrm{min})$ were infused. During the hypotensive period, $\mathrm{SpO}_{2}$ was maintained at $50-80 \%$ and ECMO flow was maintained at $3.5-6.0 \mathrm{~L} / \mathrm{min}$. At $1 \mathrm{hr}$ after the catecholamine infusion, BP was $95 / 70 \mathrm{mmHg}$ with HR of 175 / min. ABGA with $\mathrm{FiO}_{2}$ of 1.0 showed $\mathrm{pH}, 7.221 ; \mathrm{PO}_{2}, 49.6 \mathrm{mmHg}$; $\mathrm{PCO}_{2}, 57.6 \mathrm{mmHg} ; \mathrm{SaO}_{2}, 75 \% ; \mathrm{HCO}_{3}{ }^{-}, 23.1 \mathrm{mmol} / \mathrm{L}$. After the right internal jugular vein was accessed for cannulation, the ECMO venous drainage became sufficient. He was transferred to the ICU on $100 \%$ oxygen with ambu bagging. Postoperative ABGA with $\mathrm{FiO}_{2}$ of 1.0 showed pH, 7.25; $\mathrm{PO}_{2}, 57 \mathrm{mmHg}$; $\mathrm{PCO}_{2}, 51.9 \mathrm{mmHg} ; \mathrm{SaO}_{2}, 84 \%$; $\mathrm{HCO}_{3}{ }^{-}, 22.6 \mathrm{mmol} / \mathrm{L}$. A chest radiograph revealed bilateral interstitial edema in both lungs (Fig. 1). Transthoracic echocardiography showed preserved LV systolic function. A pulmonary artery catheter was placed postoperatively, and the cardiac index was $3.7 \mathrm{~L} / \mathrm{min} / \mathrm{m}^{2}$. On the seventh postoperative day, the patient was weaned from ECMO. Three weeks after ECMO weaning, he was discharged from the hospital without serious pulmonary or neurological complications. ABGA showed $\mathrm{pH}, 7.438 ; \mathrm{PO}_{2}, 97.8 \mathrm{mmHg}$; $\mathrm{PCO}_{2}, 43.2 \mathrm{mmHg} \mathrm{SaO}_{2}, 97.9 \% ; \mathrm{HCO}_{3}{ }^{-}, 28.6 \mathrm{mmol} / \mathrm{L}$.

ECMO by means of peripheral cannulation is an established therapeutic strategy in patients with cardiopulmonary failure and has been used successfully to manage acute reversible pulmonary failure [4]. Surgical procedures during ECMO have been performed in some patients, but no reports are available about applying ECMO under general anesthesia. Considering our patient's pulmonary status, we performed intravenous anesthesia with propofol rather than volatile anesthetics. Propofol is a hypnotic agent whose pharmacological properties make it extremely well suited to sedation and anesthesia. Because of its high potency and the respiratory and cardiovascular complications that can result, propofol should only be used when strict precautionary measures are observed. In our patient, BP decreased to $80 / 40 \mathrm{mmHg} 30 \mathrm{~min}$ after the propofol infusion, and HR increased to 150 /min but did not improve for about $1 \mathrm{~h}$. In addition to chemical pneumonitis, we assumed that propofol induced the hypotension and tachycardia. Propofol has been reported to stimulate nitric oxide (NO) activity and showed a concentration-dependent increase in NO production by neutrophils [5]. It can be hypothesized that severe hypotension occurs during anesthesia. The implication for NO produced during nitric acid exposure and propofol infusion worsened the hypotension in this case.

In conclusion, we experienced unexpected hypotension and tachycardia during propofol infusion for ECMO cannulation in a patient with a nitric acid inhalation injury. We suggest that anesthesiologists should be aware of the clinical features of nitric acid inhalation injury and the effect on possible hemodynamic derangement with use of the intravenous anesthetic such as propofol.

\section{References}

1. Murphy CM, Akbarnia H, Rose SR. Fatal pulmonary edema after acute occupational exposure to nitric acid. J Emerg Med 2010; 39: 39-43.

2. Hajela R, Janigan DT, Landrigan PL, Boudreau SF, Sebastian S. Fatal pulmonary edema due to nitric acid fume inhalation in three pulpmill workers. Chest 1990; 97: 487-9.

3. Bur A, Wagner A, Röggla M, Berzlanovic A, Herkner H, Sterz F, et al. Fatal pulmonary edema after nitric acid inhalation. Resuscitation 1997; 35: 33-6.

4. Lindén V, Palmér K, Reinhard J, Westman R, Ehrén H, Granholm T, et al. High survival in adult patients with acute respiratory distress syndrome treated by extracorporeal membrane oxygenation, minimal sedation, and pressure supported ventilation. Intensive Care Med 2000; 26: 1630-7.

5. Vasileiou I, Xanthos T, Koudouna E, Perrea D, Klonaris C, Katsargyris A, et al. Propofol: a review of its non-anaesthetic effects. Eur J Pharmacol 2009; 605: 1-8. 